\title{
SHORT-TERM RESULTS IN EVALUATING A GINGIVA- ADHESIVE HYDROPHOBIC-CHLORHEXIDINE-GEL FOR CHRONIC PERIODONTITIS
}

\author{
CIPRIAN SARBU ${ }^{1}$, DARIAN RUSU ${ }^{1}$, HORIA CĂLNICEANU ${ }^{2}$, \\ ADRIAN KASAJ ${ }^{3}$, STEFAN ADRIAN PETRUTIU ${ }^{4}$, \\ ALEXANDRA ROMAN ${ }^{4}$, ANDRADA SOANC $\breve{A}^{4}$, ALINA PICOŞ ${ }^{5}$, \\ STEFAN IOAN STRATUL ${ }^{1}$, HOLGER JENTSCH ${ }^{6}$
}

\author{
${ }^{1}$ Department of Periodontology, Victor Babes University of Medicine and \\ Pharmacy, Timisoara, Romania \\ ${ }^{2}$ Department of Dental Medicine, Faculty Of Medicine and Pharmacy, Oradea \\ University, Romania \\ ${ }^{3}$ Department of Conservative Dentistry and Periodontology, Johannes Gutenberg \\ University, Mainz, Germany \\ ${ }^{4}$ Department of Periodontology, Iuliu Haţieganu University of Medicine and \\ Pharmacy, Cluj-Napoca, Romania \\ ${ }^{5}$ Department of Prosthodontics, Iuliu Haţieganu University of Medicine and \\ Pharmacy, Cluj-Napoca, Romania \\ ${ }^{6}$ Center for Periodontology, Department of Conservative Dentistry and \\ Periodontology, University of Leipzig, Germany
}

\section{Abstract}

Background and Aims: Oral mucosa and interproximal spaces of the teeth could favor the colonization of periodontopathogenic bacteria, which could be targeted by chemical antiplaque agents such as chlorhexidine, present in different oral hygiene products, thus improving the control of biofilm growth and delaying microbial accumulation. The study aimed to evaluate whether the use of a hydrophobic gel with good gingival adhesion for 14 days after the scaling and root planing of patients with chronic periodontitis would improve the treatment outcome, when compared with the use of a regular hydrophyllic gel.

Material and Methods: Patients with moderate disease were included in two study groups. At baseline and 3 months after the treatment the following parameters were recorded: pocket depth, Approximal Plaque Index, Modified Gingival Index, Simplified Oral Hygiene Index, bleeding on probing. Patients received scaling and root planing in two sessions at 24 hours interval. After the treatment, patients in the test group applied the hydrophobic adhesive chlorhexidine gel once a day, every other day, while in the control group the gel was used twice daily.

Results: Both treatments resulted in significant improvement in all clinical indices, except Approximal Plaque Index, which deteriorated significantly in both groups. Three months after mechanical treatment, the mean probing depth changed in the test group from $4.16 \pm 0.45 \mathrm{~mm}$ to $2.80 \pm 0.42 \mathrm{~mm}$, and in the control group from $4.16 \pm 0.30$ to $2.69 \pm 0.19$.

Conclusions: Both adjunctive anti-infective therapies induced clinical improvement 3 months from baseline. The differences between the two treatments were not statistically significant.

Keywords: chronic periodontitis, treatment, chlorhexidine, dental scaling

Manuscript received: 06.08.2014

Accepted: 14.08.2014

Address for correspondence: veve_alexandra@yahoo.com 


\section{Introduction}

Tooth loss is primarily caused by periodontal disease and dental caries [1]. Plaque accumulation is the most important factor in the development of both diseases. The dental plaque is a dynamic structure and it is more precisely considered a biofilm formed by a microbial community growing in an extracellular polysaccharide matrix [2]. Its structure has multiple channels constituted in a tridimensional network serving for nutrient transportation as well as metabolites or genetic material. This allows interactions between the bacterial species, but also the protection of the microorganisms from the action of antiseptics, antibiotics and host immunity [3]. The accumulation of dental biofilms at the juxta-gingival level or in subgingival areas increases the bacterial load and induces an inflammatory response in the gingival surrounding tissues [4]. As the biofilm becomes older, a shift in its composition is also observed from a flora composed mostly by Streptococcus spp. and Actinomyces spp. [5] to a flora containing many of the recognized Gram-negative periodontopathogenic bacteria. Gingivitis is frequently undiagnosed due to the lack of pain and minor inflammatory expression [6,7]. Further changes in the composition of the subgingival biofilm and a particular host susceptibility induce in some individuals the destruction of profound periodontal structures and the development of periodontitis. Periodontal disease is currently considered to be caused by a dysbiosis of the periodontal microbiota, that is, a change in the relative abundance of individual components of the microbiota compared with their abundance in health [8]. Gingivitis is totally reversible when correctly treated and reinstatement of proper hygiene habits is made [9], but left untreated it can lead to severe and irreversible periodontitis [6], impairing the oral quality of life, causing pain, eating difficulties, aesthetic problems and even tooth loss [10].

Epidemiological studies show the important overall burden of gingivitis and periodontitis. The prevalence of gingivitis is reported to be up to $90-98 \%$ in developed as well as in less economically developed countries. The prevalence of severe periodontal disease is reported to be around $20 \%$ in adults aged between 35 and 44 years [7].

As the presence of gingivitis is a pre-requisite for the development of periodontitis [11], the screening and treatment of plaque-induced gingivitis, but also the prevention of gingival inflammation, seem to be important issues in preventing the development of periodontitis. The first step in treating already installed periodontitis is the elimination of soft and hard deposits from the teeth in order to decrease the bacterial load and re-induce local subgingival homeostasis. The non-surgical periodontal therapy, consisting in powered and manual scaling and root planning (SRP), is considered the cornerstone of the periodontal therapy [3].

Besides the professional cleaning, an important role in the management of gingivitis and periodontitis is held by the personal plaque removal and control. Personal hygiene habits should include tooth brushing with a correct technique, interdental space cleaning and chemical plaque control. In most circumstances the ideal oral hygiene habits are difficult to be performed by the patients. This is why clinicians and scientists have tried to find an antimicrobial agent that would prevent or slow down plaque formation $[12,13]$. Clorhexidine is at the moment the "gold standard" antiseptic used in the periodontal therapy. Its efficacy was questioned many times in more than three decades of use, but it still remains the standard for comparing other oral antiseptics [14]. Clorhexidine is present in different formulations: mouthwash, gels, sprays, toothpaste and even chewing gum [15].

Clorhexidine is a cationic bisbiguanide, having a broad antibacterial activity associated with a low toxicity. Its spectrum is represented by gram-negative and grampositive bacteria, yeasts, dermatophytes and some lipophilic viruses [14]. It adheres to oral mucosa and tooth structures, presenting a long substantivity, which is the ability of an agent to be retained in particular surroundings $[3,16]$. Its effect can last up to 12 hours [17], due to the properties that allow the clorhexidine molecules to bind to the oral mucosa, teeth, acquired pellicle and salivary proteins. The capacity to attach to the tooth surface also induces the most known side-effect of the clorhexidine - tooth staining [18], due to the precipitation reaction between the clorhexidine bound to the teeth and alimentary chromogens [19].

The present research aimed to evaluate, in a randomized controlled study, whether the daily use of a hydrophobic clorhexidine gel with good gingival adhesion (durimplant ${ }^{\circledR}$, artis Pharma $\mathrm{GmbH} \&$ Co. KG, Dettenhausen, Germany) 14 days after the SRP of patients with chronic periodontitis would improve the short-term treatment outcome, when compared with the use of a regular hydrophilic gel. Durimplant ${ }^{\circledR}$ is a hydrophobic gingiva-adhering gel with a complex composition, low solubility in saliva and increased mucosal substantivity, due to its content of hypromellose (hydroxypropylmethylcellulose). Its active ingredients are: essential oils of Salvia lavandulifolia and Mentha piperita, thymol, chlorhexidine digluconate and diacetate, allantoin (with cell-regenerating and wound-healing properties).

\section{Material and Methods}

Study group. The patients were chosen from a group of subjects referred to the Department of Periodontology of the Victor Babes University of Medicine and Pharmacy of Timisoara, Romania. The study protocol was described to the patients and an informed consent was obtained. The study was approved by the Ethics Committee of the Victor Babes University of Medicine and Pharmacy of Timisoara (approval No. 12/14.12.2009). The study was conducted according to the WMA Declaration of Helsinki, as amended in 2008. The study took place between January 2010 and 
May 2011. The study compared the efficacy of SRP when associated with an adjunctive antimicrobial hydrophobic gingiva-adhering gel with complex composition

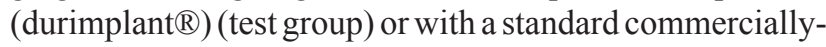
available $1 \%$ chlorhexidine digluconate water-soluble gel with reduced adhesion to gingiva (Chlorhexamed 1\% gel, GlaxoSmithKline, Bretford, UK) (control group).

The study included patients with: 1) moderate chronic periodontitis, 2) no periodontal therapy during the last two years, and 3) no antibiotic or anti-inflammatory drugs intake during the last 6 months before baseline examination. According to the Center for Disease Control and the American Academy of Periodontology (CDC-AAP) definition, patients with moderate chronic periodontitis were considered as presenting 2 or more interproximal sites with $\geq 4 \mathrm{~mm}$ clinical attachment level (CAL) - not on the same tooth - or 2 or more interproximal sites with $\geq 5$ $\mathrm{mm}$ probing depth (PD), also not on the same tooth [20]. Patients were excluded if they were pregnant or nursing or had diseases with influence on the periodontal disease and its treatment.

Investigator training. All participating investigators attended two training and calibration meetings, in which they received instructions on the development of the study, case selection, measurement techniques, nonsurgical treatment protocol, data compilation sheets and their precise role in the study. The meetings were coordinated by a senior periodontist.

Clinical measurements. Clinical measurements and photographs were taken at baseline and 3 months after the mechanical treatment. The measurements that took as a reference point the cement-enamel junction were performed with a manual periodontal probe (UNC-15 periodontal probe, Hu-Friedy, Chicago, IL) and were rounded up to the nearest millimeter. The following parameters were assessed: 1) the Approximal Plaque Index API [21]; 2) the Simplified Oral Hygiene Index OHI-S [22]; 3) the Modified Gingival Index MGI [23]; 4) the Gingival Bleeding Index BOP [24]; 5) the PD; 6) the gingival recession (GR); 7) the CAL. PD, GR and AL were considered according to the standard clinical definitions and were measured in 6 points per tooth [20].

Clinical procedure and post-surgical care. Following professional cleaning and extensive, repeated oral hygiene instructions until the API reached a value $\leq 35 \%$, a fullmouth SRP was performed under local anesthesia in two sessions within 24 hours, using ultrasonic (Newtron ${ }^{\circledR}$ Booster, Satelec Acteon, Merignac Cedex, France) and hand instruments (reduced set of Gracey Standard Curettes, Hu-Friedy Manufacturing Co., Chicago, IL, USA). For the test group, at the end of the SRP, durimplant ${ }^{\circledR}$ was applied by gentle rubbing on the marginal gingiva. The subjects in the test group were instructed to apply durimplant $\AA$ on the marginal gingiva for the next 14 days, once every second day, immediately after the evening tooth- brushing. In the subjects in the control group, at the end of the SRP, a standard, water-soluble $1 \%$ chlorhexidine gel (Chlorhexamed 1\% gel) was applied in the same way. The subjects in the control group were instructed to apply for 14 days the $1 \%$ chlorhexidine gel on the marginal gingiva in the morning and in the evening every day, immediately after the tooth-brushing.

After the SRP, the patients performed carefully supervised, normal oral hygiene with toothbrushes and interdental brushes. After 3 months, the patients underwent supportive periodontal care by a prophylaxis assistant, in which the clinical measurements were recorded before the mechanical instrumentation.

Statistical analyses. The collected data were processed using the SPSS v. 16 software package. The Wilcoxon nonparametric test was used to compare the mean differences between the baseline and 3 months afterwards, and the Mann-Whitney non-parametric test was used to compare the mean differences between the groups.

\section{Results}

A total of 28 eligible patients were included in the study and were subject to randomization. Four patients were lost because they did not attended the 3 month follow-up examination; 24 patients completed the study: 14 patients in the test group and 10 patients in the control group. The mean age of the patients was $47.4 \pm 5.3$ for the test group and $47.9 \pm 5.9$ for the control group. The healing after the full-mouth scaling procedure was uneventful and no adverse effects were noted during the treatment.

The values of the investigated parameters for the test and control group at baseline and 3 months later, are shown in Table I. The differences between baseline and after 3 months values and their statistical significances were provided for each group.

Table II presents the results of the Mann-Whitney non-parametric test, used to compare the mean differences between the groups.

Both treatments resulted in significant improvement in all clinical indices, except OHI-S. However, good OHI-S scores were recorded, for both groups, in both baseline and 3 months examinations. A worsening of API index was noticed after 3 month, in both groups. Three months after application, a significant mean reduction of PD was recorded in the test group $(1.36 \pm 0.43 \mathrm{~mm})$ and in the control group $(1.46 \pm 0.40 \mathrm{~mm})$. The reduction of $\mathrm{PD}$ seems important as it could further reduce the surgical treatment need.

\section{Discussion}

The aim of the present study was to observe the differences in the clinical outcomes of two antiinfective treatment approaches used as adjunctive therapies after SRP. A 14 days treatment regimen with an adherent gingival chlorhexidine gel (durimplant $($ ) ) was compared 
Table I. Clinical parameters at baseline and after 3 months for each of the study groups (durimplant ${ }^{\circledR}$ and Chlorhexamed $($ )

\begin{tabular}{lccccc}
\hline $\begin{array}{l}\text { Clinical } \\
\text { parameter }\end{array}$ & Study group & Baseline & 3 months & $\begin{array}{c}\Delta \text { baseline }-\mathbf{3} \\
\text { months }\end{array}$ & Significance \\
\hline PD & Durimplant & $4.16 \pm 0.45$ & $2.80 \pm 0.42$ & $1.36 \pm 0.43$ & $\begin{array}{c}p<0.001 \\
p<0.01\end{array}$ \\
& Chlorhexamed & $4.16 \pm 0.30$ & $2.69 \pm 0.19$ & $1.46 \pm 0.40$ & \\
& & & & & \\
& Durimplant & $19.83 \pm 7.24$ & $40.45 \pm 18.91$ & $-20.62 \pm 21.47$ & $p<0.01$ \\
& Chlorhexamed & $22.00 \pm 6.28$ & $40.44 \pm 16.64$ & $-18.44 \pm 17.83$ & $p<0.05$ \\
OHI-S & & & & \\
& Durimplant & $0.43 \pm 0.29$ & $0.57 \pm 0.61$ & $-0.14 \pm 0.61$ & $n . S$. \\
MGI & Chlorhexamed & $0.60 \pm 0.29$ & $0.46 \pm 0.19$ & $0.14 \pm 0.24$ & $n . S$. \\
& & & & & \\
& Durimplant & $0.96 \pm 0.39$ & $0.22 \pm 0.18$ & $0.74 \pm 0.42$ & $p<0.001$ \\
BOP & Chlorhexamed & $1.23 \pm 0.13$ & $0.30 \pm 0.24$ & $0.93 \pm 0.29$ & $p<0.01$ \\
& Durimplant & $55.79 \pm 19.71$ & $25.26 \pm 18.30$ & $30.53 \pm 18.23$ & $p<0.01$ \\
& Chlorhexamed & $66.06 \pm 13.97$ & $26.94 \pm 14.72$ & $39.13 \pm 13.13$ & $p<0.01$ \\
\hline
\end{tabular}

Table II. Changes in the clinical parameters 3 months after the treatment between the studied groups using durimplant ${ }^{\circledR}(\mathrm{n}=14)$ and Chlorhexamed $\AA(n=10)$

\begin{tabular}{|c|c|c|c|c|}
\hline Clinical parameter & $\mathbf{T x}$ & $\Delta$ baseline -3 months & $\Delta \mathbf{t x}$ & Significance \\
\hline PD & $\begin{array}{c}\text { Durimplant } \\
\text { Chlorhexamed }\end{array}$ & $\begin{array}{l}1.36 \pm 0.43 \\
1.46 \pm 0.40\end{array}$ & -0.1 & n.s. \\
\hline OHI_S & $\begin{array}{l}\text { Durimplant } \\
\text { Chlorhexamed }\end{array}$ & $\begin{array}{l}-20.62 \pm 21.47 \\
-18.44 \pm 17.83\end{array}$ & -2.18 & n.s. \\
\hline MGI & $\begin{array}{l}\text { Durimplant } \\
\text { Clorhexamed }\end{array}$ & $\begin{array}{c}-0.14 \pm 0.61 \\
0.14 \pm 0.24\end{array}$ & -0.28 & n.s. \\
\hline POD & $\begin{array}{l}\text { Durimplant } \\
\text { Chlorhexamed }\end{array}$ & $\begin{array}{l}0.74 \pm 0.42 \\
0.93 \pm 0.29\end{array}$ & -0.19 & n.s. \\
\hline & $\begin{array}{c}\text { Durimplant } \\
\text { Chlorhexamed }\end{array}$ & $\begin{array}{l}30.53 \pm 18.23 \\
39.13 \pm 13.13\end{array}$ & -8.6 & n.s. \\
\hline
\end{tabular}

with the use of a commercially-available $1 \%$ chlorhexidingel (Chlorhexamed $\left.{ }^{\circledR}\right)$. Positive effects were associated with both chlorhexidine gel formulations but no significant statistical differences were noticed between the study groups. In fact no improved effect was observed due to the synergic activity of the additives (e.g. thymol, peppermint and sage oil, allantoin) included in durimplant ${ }^{\circledR}$ or to the extended presence on the gingiva of the hydrophobic formulation. The results are not surprising, having in view the efficacy of chlorhexidine molecule despite its formulation. Even if it was presumed that durimplant ${ }^{\circledR}$ would have a better effect on clinical outcomes due to its increased substantivity and the additional chemical substances with proved anti-inflammatory effects, the gingival persistence of chlorhexidine from a standard formulation seemed to be long enough to elicit its antiplaque effects.

Currently, the most commonly used procedure for the treatment of periodontitis is the use of mechanical disruption of the subgingival biofilm by SRP. The clinical and the microbiological response to this nonsurgical therapy of chronic periodontitis has been well documented. Following SRP at sites with PD of 4-6 mm, clinicians should expect a mean reduction in PD of approximately 1 $\mathrm{mm}$ and a gain of clinical attachment level of approximately $0.5 \mathrm{~mm}$. In deeper sites $(>7 \mathrm{~mm})$, the reduction in PD averages approximately $2 \mathrm{~mm}$ and the gain in clinical attachment level averages about $1 \mathrm{~mm}$ [25]. A rigorous personal plaque control should follow the professional one in order to obtain good results after the therapy. However, several studies have shown that the mechanical disruption is insufficient for altering the composition of the flora so as to prevent a recurrence of infection at the affected sites [26].

Recent studies have demonstrated that the microorganisms involved in the etiology of gingivitis and periodontitis accumulate on several soft tissue surfaces of the mouth, which serve as a source of bacteria for the colonization of tooth surfaces. These areas are targeted by chemical antiplaque agents present in different oral hygiene 
products as they could reach the soft tissue surfaces, improving the control of biofilm growth and delaying microbial accumulation. Adjunctive antiseptics following professional plaque control may improve the clinical benefits but they cannot replace the mechanical therapy. Many substances in different formulations are today available [12]. The present study chose chlorhexidine as adjunctive therapy after SRP as it has been proven many times as the most effective agent against plaque. Chlorhexidine is among the most tested compounds [12]. Rinsing with $10 \mathrm{ml}$ of $0.2 \%$ chlorhexidine gluconate mouthwash, for 1 minute twice daily, completely prevented the formation of plaque and gingivitis. Once the rinsing with chlorhexidine was terminated, plaque formed once more [17]. Chlorhexidine molecules are initially adsorbed on the enamel surface or the salivary pellicle, enabling it to act over a long period after application, so that bacterial adhesion is inhibited [27]. The major advantage of chlorhexidine over most other compounds lies in its substantivity, which is due to its ability to bind to the carboxyl groups of the mucins that cover the oral mucosa and to be steadily released from these areas in an active form, displaced by the salivary calcium ions [28].

Chlorhexidine is also known to be bacteriostatic against most oral bacteria [29]. In high concentrations it is bactericidal and acts as a detergent by damaging the bacterial cell membrane [30]. Bacterial counts in the saliva consistently drop to between 10 and $20 \%$ of baseline after single rinses and remain at this level for at least 7 hours and probably more than 12 hours. Therefore, chlorhexidine is used as a positive control in many clinical trials of new mouth-rinse formulations and is considered the "gold standard". For indications where plaque control is the main focus such as post-surgery wound-healing or after SRP, chlorhexidine-based products remain the first choice [31]. The adjunctive use of chlorhexidine-based formulations after SRP may address to an insufficient compliance of the patients and to colonized soft tissue surfaces and may result in significant additional clinical and microbiological improvements over SRP alone [32,33]. The significant improvements of inflammation indices after 3 month following SRP, observed by the present study, proved once more its antimicrobial properties. The non-significant changes in OHI-S values after 3 months from baseline may be due to the already good scores at baseline as a consequence of a supervised oral hygiene.

Different chlorhexidine formulations are currently used: mouthwashes, gels, varnishes, or implantable antimicrobial delivery devices (PerioChip ${ }^{\circledR}$, poly[dl-lactic-coglycolic acid]-based delivery system) all demonstrating a biological activity against bacterial populations relevant in periodontitis [26,34-36]. Both gels used by the present study demonstrated enough gingival persistence to elicit adjunctive antimicrobial effects that induced the favorable clinical outcomes.
The present study used the one-stage, full-mouth SRP approach, that is, the completion of full-mouth SRP in a $24 \mathrm{~h}$ interval in order to prevent the spreading of pathogenic bacteria from untreated pockets to the already debrided ones [32].

One of the limitations of the present research is the short term follow-up period. In fact, this study reported only the partial results of a more extensive controlled study with a similar design, also recording microbiological and enzymatic outcomes over one year period after SRP.

\section{Conclusions}

Both adjunctive anti-infective therapeutic approaches were associated with clinical improvement 3 months after baseline. However, the differences between the two treatments using two chlorhexidine-based formulations were not statistically significant.

The well-known positive effects of chlorhexidine on reducing inflammation were once more proved by significant reductions of inflammation indices recorded by the present study.

Tooth brushing alone is not effective in removing plaque, mostly in interdental areas, and consequently, chemical antiplaque control using chlorhexidine gels may be justified to overcome the limitations of tooth brushing.

\section{References}

1. Neely AL, Holford TR, Löe H, Anerud A, Boysen H. The natural history of periodontal disease in humans: risk factors for tooth loss in caries-free subjects receiving no oral health care. J Clin Periodontol. 2005;32(9):984-993.

2. Costerton JW, Lewandowski Z, DeBeer D, Caldwell DE, Korber DR, James G. Biofilms, the customized microniche. J Bacteriol. 1994;176:2137-2142.

3. Darby I. Non-surgical management of periodontal disease. Aust Dent J. 2009;54 Suppl 1:S86-95.

4. Marsh PD. Microbial ecology of dental plaque and its significance in health and disease. Adv Dent Res. 1994;8(2):263271.

5. Dalwai F, Spratt DA, Pratten J. Modeling shifts in microbial populations associated with health or disease. Appl Environ Microbiol 2006;72(5):3678-3684.

6. Lang NP, Schätzle MA, Löe H. Gingivitis as a risk factor in periodontal disease. J Clin Periodontol. 2009; 36 Suppl 10:3-8.

7. Riley P, Lamont T. Triclosan/copolymer containing toothpastes for oral health. Cochrane Database Syst Rev. 2013;12:CD010514. doi: 10.1002/14651858.CD010514.pub2.

8. Hajishengallis G, Darveau RP, Curtis MA. The keystone pathogen hypothesis. Nat Rev Microbiol. 2012;10(10):717-725.

9. Löe H, Theilade E, Jensen SB. Experimental gingivitis in man. J Periodontol 1965;36: 177-187.

10. Gerritsen AE, Allen PF, Witter DJ, Bronkhorst EM, Creugers NH. Tooth loss and oral health-related quality of life: a systematic review and meta-analysis. Health Qual Life Outcomes. 2010;8:126.

11. Axelsson P. Mechanical plaque control. In: Lang N, Karring T (eds). Proceedings of the 1st European Workshop on Periodontics, 1993. London: Quitessence, 1994:219-243. 
12. Baehni PC, Takeuchi Y. Anti-plaque agents in the prevention of biofilm-associated oral diseases. Oral Dis. 2003;9 Suppl 1:23-29.

13. Teles RP, Teles FR. Antimicrobial agents used in the control of periodontal biofilms: effective adjuncts to mechanical plaque control? Braz Oral Res. 2009;23 Suppl 1:39-48.

14. Jones CG. Chlorhexidine: is it still the gold standard? Periodontol 2000. 1997; 15:55-62.

15. Addy M, Moran JM.Clinical indications for the use of chemical adjuncts to plaque control: chlorhexidine formulations. Periodontol 2000. 1997; 15:52-54.

16. Denton GW. Chlorhexidine. In: Block SS (ed). Disinfection, sterilization and preservation. 4th ed. Philadelphia: Lea and Febiger, 1991: 274-289.

17. Schiott CR. Effect of chlorhexidine on the microflora of the oral cavity. J Periodont Res. 1973;8(suppl):7-10.

18. Lang NT, Brecx MC. Chlorhexidine digluconate - an agent for chemical plaque control and prevention of gingival inflammation. J Periodont Res. 1986;21(suppl):74-89.

19. Addy M, Wade W, Goodfield S. Staining and antimicrobial properties in vitro of some chlorhexidine formulations. Clin Prev Dent. 1991;6:13-17.

20. Page RC, Eke PI. Case definitions for use in population based surveillance of periodontitis. J Periodontol 2007;78(Suppl. 7):1387-1399.

21. Lange DE, Plagmann HC, Eenboom A, Promesberger A. Clinical methods for the objective evaluation of oral hygiene. Dtsch Zahnarztl Z. 1977;32(1):44-47.

22. Green JC, Vermillon JR. The simplifield oral hygene index. J Am Dent Assoc. 1964;68:7-13.

23. Lobene RR, Weatherford T, Ross NM, Lamm RA, Menaker L. A modified gingival index for use in clinical trials. Clin Prev Dent. 1986;8(1):3-6.

24. Ainamo J, Bay J. Problems and proposals for recording gingivitis and plaque. Int Dent J. 1975;25(4):229-235.

25. Deas DE, Mealey BL. Response of chronic and aggressive periodontitis to treatment. Periodontol 2000. 2010;53:154-166.

26. Yue IC, Poff J, Cortés ME, Sinisterra RD, Faris CB, Hildgen
P, Langer R, Shastri VP. A novel polymeric chlorhexidine delivery device for the treatment of periodontal disease. Biomaterials. 2004;25(17):3743-3750.

27. Pratten J, Smith AW, Wilson M. Response of single species biofilms and microcosm dental plaques to pulsing with chlorhexidine. J Antimicrob Chemother. 1998;42(4):453-459.

28. Greenstein G, Berman C, Jaffin R. Chlorhexidine. An adjunct to periodontal therapy. J Periodontol. 1986;57(6):370-377.

29. Shapiro S, Giertsen E, Guggenheim B. An in vitro oral biofilm model for comparing the efficacy of antimicrobial mouthrinses. Caries Res. 2002;36(2):93-100.

30. Meurman JH. Ultrastructure, growth, and adherence of Streptococcus mutans after treatment with chlorhexidine and fluoride. Caries Res. 1988;22(5):283-287.

31. Van Leeuwen MP, Slot DE, Van der Weijden GA. Essential oils compared to chlorhexidine with respect to plaque and parameters of gingival inflammation: a systematic review. J Periodontol. 2011;82(2):174-194.

32. Teughels W, Dekeyser C, Van Essche M, Quirynen M.Onestage, full-mouth disinfection: fiction or reality? Periodontol 2000. 2009;50:39-51.

33. Faveri M, Gursky LC, Feres M, Shibli JA, Salvador SL, de Figueiredo LC. Scaling and root planing and chlorhexidine mouthrinses in the treatment of chronic periodontitis: a randomized, placebo-controlled clinical trial. J Clin Periodontol. 2006;33(11):819-828.

34. Soskolne W, Heasman P, Stabholz A, Smart GJ, Palmer M, Flashner M, et al. Sustained local delivery of chlorhexidine in the treatment of periodontitis: a multi-center study. J Periodontol. 1997;68:32-38.

35. Heasman PA, Heasman L, Stacey F, McCracken GI. Local delivery of chlorhexidine gluconate (Perio Chip) in periodontal maintenance patients. J Clin Periodontol. 2001;28(1):90-95.

36. Puig Silla M, Montiel Company JM, Almerich Silla JM. Use of chlorhexidine varnishes in preventing and treating periodontal disease. A review of the literature. Med Oral Patol Oral Cir Bucal. 2008;13(4):E257-260. 